\title{
Etkinlikten Vazgeçme Ölçeği Geçerlik Güvenirlik Çalışması
}

DOI: $10.26466 /$ opus.689357

*

\author{
Ali Selman Özdemir* - Tebessüm Ayyıldız Durhan** - Suat Karaküçük*** \\ * Dr, Öğr, Üyesi, Uluslararası Kıbrıs Üniversitesi, Beden Eğitim ve Spor Y.O \\ E-Posta: ozdemiraliselman@gmail.com \\ ORCID: $0000-0003-1736-7602$ \\ ** Dr, Gazi Üniversitesi, Rekreasyon Bölümü \\ E-Posta: tebessum@gazi.edu.tr \\ ORCID: 0000-0003-2747-6933 \\ *** Prof. Dr., Gazi Üniversitesi, Rekreasyon Bölümü \\ E-Posta: ksuat@gazi.edu.tr \\ ORCID: 0000-0001-9144-7307
}

Öz

$\mathrm{Bu}$ çalışmanın amacı etkinlikten vazgeçme ölçeğinin geçerlik ve güvenirlik analizlerini yaparak literatüre kazandırmaktır. Araştırma test tekrar test yöntemiyle toplam 593 öğrenciden toplanan veriler ışığında yapılan analizlere dayanmaktadır. Veriler 293 katılımo ile KMO-Barlett testine tabi tutulmuş ve örneklem büyüklüğünün analizi yapmak adına uygun olduğu $(.92 ; 2232,957, p<0,001)$ belirlendikten sonra açımlayıcı faktör analizinden yararlanılmıştır. Açımlayıcı faktör analizi ile geçerli bir yapı oluşturulmaya çalışılmış, oluşturulan yapıya dair iç güvenirlik katsayıları sırasıyla .92 ve .79 bulunmasıyla yapıyı destekler düzeyde olduğu belirlenmiştir. Yapılan açımlayıcı faktör analizi sonucu kesme değeri 30 olarak alınmış, açıklanan varyans değerinin toplamda \%64,96 olduğu döndürülmüş bileşenler analizinde iki alt boyut altında toplandığı saptanmıştır. Test tekrar test yöntemiyle 300 katılımcı üzerinde yapılan ikinci veri toplama işleminden sonra yapı doğrulayıcı faktör analizi ile sınanmıştır. Doğrulayıcı faktör analizinin yap geçerliliğine kant oluşturduğu görülmektedir (RMSEA .062, SRMR 0.033, NFI 0.98, CFI 0.99, NNFI 0.98, $x^{2} / d f$ 2.13). Sonuç olarak katıllımcların etkinlikten vazgeçmelerinin belirlenmesine yönelik geliştirilen ölçüm aracınn, etkinlikten vazgeçme fenomenini ölçmede geçerli ve güvenilir bir araç olduğu belirlenmiştir.

Anahtar Kelimeler: Etkinlik, boş zaman, rekreasyon, vazgeçme, ölçek geliştirme, 


\title{
Leisure Abondonment Scale Validity And Reliability Analysis
}

\begin{abstract}
The aim of this study is to give validity and reliability analysis of the leisure abondenment to the literature. The research is based on the analysis made in the light of the data collected from 593 students using the test retest method. The data were subjected to KMO-Barlett test with 293 participants and the exploratory factor analysis was used after the determination of the sample size $(.92 ; 2232,957, p$ $<0.001$ ). A valid structure was tried to be constructed with exploratory factor analysis and internal reliability coefficients were determined to be about .92 and .79, respectively. As a result of the exploratory factor analysis, the cut-off value was taken as .30 and it was found that the variance value was $64.96 \%$ in total. After the second data collection performed on 300 participants with test retest method, the structure was tested with confirmatory factor analysis. Confirmatory factor analysis appears to provide evidence for construct validity (RMSEA .062, SRMR 0.033, NFI 0.98, CFI 0.99, NNFI $0.98, x 2 / d f 2.13)$. As a result, it was determined that the measurement tool which was developed to determine the discontinuation of the participants was a valid and reliable tool for measuring the phenomenon of discontinuation of activity.
\end{abstract}

Keywords: Activity, abondonment, scale 


\section{Giriş}

Son yirmi yılda, serbest zaman katılımına yönelik motivasyonları ve kısıtlayıcıları anlama konusunda çok çaba sarf edilmesine rağmen, bu tür etkinliklere katılımın sona erdirilmesini veya "vazgeçme" olarak adlandırılan fenomeni anlamak için sınırlı sayıda araştırma yapılmıştır. Ancak vazgeçme, bir aktiviteye katılım sıklığını azaltma veya sıklığı azaltma kararında kritik rol oynayan kısıtlayıcılarla ilişkili değildir (Fedler ve Ditton, 2001; Raymore ve diğ., 1993). 'Etkinlikten vazgeçme', bireyin yaşam seyrinde devam ettiği belirli bir boş zaman değerlendirme aktivitesini bırakmasıdır. Bugüne kadar yapılan gözlemler, etkinlikten vazgeçmenin genel olarak şu koşullar altında gerçekleştiğini göstermektedir: 1) aktiviteyi bırakmaya bilinçli bir şekilde karar vermek, 2) diş koşullar tarafından zorlanmak, 3) aktivite ile olan bağların kopması (Stebbins, 2008). 'Vazgeçme' konusunun odağı; vazgeçilen aktivitenin yerini doldurmak ya da daha cazip ve yeni bir aktivite değil, şu anki aktivitede neyin yanlış olduğu, insanların neden ayrıldığı ile ilgilidir. Stebbins (2008), insanların yaşamları boyunca bir kez de olsa boş zaman uğraşları arasında yer alan, sevdikleri bir aktiveyi bırakmakla yüzleştiklerini ya da bir k1rılma noktası yaşadıklarından söz ederken, vazgeçmenin gerçekleştiği koşulları beş ana başılı altında toplayarak olasılıkları aşağıdaki gibi özetlemiştir; İradeye Bağlı Vazgeçme;

1. Katılımc faaliyete olan ilgisini kaybeder.

2. Katılımcı ilgisini korur, ancak daha çekici bir aktiviteyle tanışır ve bu da birinciyi terk etmesine yol açar. $\mathrm{Bu}$, her iki faaliyetin de sürdürülmesinin mevcut olmayanlardan daha fazla zaman veya para veya her ikisini de gerektireceğini varsayar.

Sosyal Psikolojik Koşullara Bağlı Vazgeçme;

3. Katılımcı, büyük ölçüde kontrolünün ötesinde sosyal baskılarla faaliyetten ayrilmaya zorlanır.

4. Katılımcı, büyük ölçüde kontrolünün ötesinde sosyal psikolojik baskılarla faaliyetten ayrılmaya zorlanır.

5. Katılımc1, sosyal destek eksikliği nedeniyle faaliyetten ayrılmaya zorlanir.

Fiziksel Koşullara Bağlı Vazgeçme;

6. Katılımc1, aktiviteyi uzun süre terk etmeye zorlanacak yaralanmaya veya hastalığa maruz kalır. 
7. Katılımcı, aktiviteyi kalıcı olarak terk etmeye zorlanacak telafi edilemez bir yaralanma veya hastalık geçirir.

8. Katılımcl, yaşlanma sürecinden ya da insanlar yaşlandıkça meydana gelen fiziksel ve zihinsel değişimlerden ötürü aktiviteyi bırakmaya zorlanir.

Coğrafi Koşullara Bağlı Vazgeçme;

9. Katılımcı, coğrafi koşullarda yaşanan değişimlere dayalı faaliyetten ayrilmaya zorlanir.

Mevzuat/Yasa/Yönetmeliklere Bağlı Vazgeçme

10. Katılımcl, yönetmelikler/mevzuatların getirdiği sınırlamalar sebebiyle aktiviteyi birakmaya zorlanır.

11. Katılımcı, başkaları tarafından öne sürülmüş ya da ispat edilmiş tasvip edilmeyen davranıslar sebebiyle aktiviteyi bırakmaya zorlanır.

12. Katılımcı, müsabaka/yarışmaya dayalı düzenlemeler/değişiklikler sebebiyle aktiviteyi bırakmaya zorlanır.

13. Katılımcı, hukuki ya da ahlaki kuşkulara dayalı önlem alma sebebiyle aktiviteyi bırakmaya zorlanır.

Bir etkinliği sürdürmekten vazgeçme kararı, bir etkinliğe katılmaya başlama kararından kavramsal olarak farklı tanımlanmıştır (Backman ve Crompton, 1989). Vazgeçme olgusunun doğası, kavrama ait tanım ve açılamalara kıyasla tam olarak anlaşılmamıştır. Özellikle; vazgeçme süreci, bu sürecin nasıl yönetildiği, katılımcının kim olduğu, bireylerin yaşantıları ve diğer boş zaman değerlendirme tercihleri üzerinde ne anlama geldiğinin anlaşılması açısından yeterince aydınlatma yapılmamıştır (Brent ve diğ., 2018).

Bu ölçeğin alanyazına kazandırılması, rekreasyonel kısıtlayıcıları aydınlatma, bunlarla ilgili uzlaşma stratejilerini belirleme, kısıtlayıcıların aktivite katılımına olan etkilerini azaltma ya da bu etkileri önleme yolların belirleme süreci açısından önemlidir. Benzer şekilde, bireylerin boş zamanlara katılma ve katılımlarını sürdürme motivasyonları deneysel ve kavramsal olarak araştırılmıştır (Chen ve Pang, 2012).

Alanyazın incelendiğinde, bireylerin rekreasyonel etkinliklere katılımlarını sonlandırma ya da aktiviteden vazgeçme davranışları üzerine sınırlı sayıda araştırmanın olduğu görülmektedir (Boothby ve diğ., 1981; Tsai ve Coleman, 1999; Fedler ve Ditton, 2001; Stebbins, 2008; Sutton ve diğ., 2009; Beaton, 2010). Stebbins (2008), etkinlikten vazgeçme için bir tipoloji öneren ilk araştırmacı olmakla beraber, "azimle sürdürülen bir faaliyetten vazgeçmenin 
kişisel krizini" araştırmanın bir ihtiyaç olduğunu belirtmektedir. Bu çalışmada, Stebbins'in (2008) vazgeçme fenomeni üzerine öne sürdüğü olasılıklardan yararlanılarak geliştirilen 'Etkinlikten Vazgeçme Ölçeği'nin geçerlik ve güvenirliğinin test edilmesi amaçlanmaktadır. Bu ölçekle birlikte, özellikle bir boş zaman aktivitesinin terk edilmesinin bireyler tarafından nasıl tecrübe edildiğinin ve yönetildiğinin araştırılarak, bu süreçteki kilit etkenlerin tanımlanması, böylece Stebbins' in (2008) tipolojisinden elde edilen bilgilerin ampirik bulgular sağlanarak geliştirilmesi hedeflenmektedir.

\section{Yöntem}

\section{Çalışma grubu}

Araştırmada yer alan veriler Zonguldak Bülent Ecevit Üniversitesinde farklı fakültelerde öğrenim gören toplam 593 öğrenciden elde edilmiştir. Oluşturulan denemelik form test tekrar test yöntemiyle 293 katılımc üzerinde sınanmış ve analizler gerçekleştirilmiştir. Yapı geçerliğini kanıtlamak adına aynı grup üzerinde ikinci test gerçekleştirilmiş ve 300 katılımcıdan elde edilen veriler doğrultusunda doğrulayıc faktör analizi uygulanmıştır.

\section{Verilerin analizi}

Veriler 293 katılımc ile KMO-Barlett testine tabi tutulmuş ve örneklem büyüklüğünün analizi yapmak adına uygun olduğu belirlendikten sonra açımlayıcı faktör analizinden yararlanılmıştır. Açımlayıcı faktör analizi ile geçerli bir yapı oluşturulmaya çalışılmış, oluşturulan yapıya dair iç güvenirlik katsayıları yapıyı destekler düzeyde olarak saptanmıştır. Test tekrar test yöntemiyle 300 katılımcı üzerinde yapılan ikinci veri toplama işleminden sonra yapı doğrulayıc faktör analizi ile sınanmıştır. Etkinlikten vazgeçmeye yönelik geçerli ve güvenilir bir yapıda olduğu analizler sonucu belirlenmiştir. Elde edilen bulgulara aşağıda yer verilmektedir. 


\section{Bulgular}

Tablo 1. Etkinlikten vazgeçme ölçeği KMO ve Barlett Testi sonuçlar

\begin{tabular}{lll}
\hline KMO ve Bartlett's Testi & & \\
\hline Kaiser-Meyer-Olkin Örneklem Uyum Ölçüsü & & 0,921 \\
\hline Barlett Küresellik Testi & $\mathrm{x}^{2}$ & 2232,957 \\
\cline { 2 - 3 } & $\mathrm{sd}$ & 78 \\
\cline { 2 - 3 } & $\mathrm{p}$ & 0,000 \\
\hline
\end{tabular}

Kaiser Meyer Olkin Örneklem Grubunun yeterliliğine yönelik test sonuçları ile Barlett Küresellik testi sonuçları örneklem grubunun yapılacak analizler için yeterli olduğunu gösterir düzeydedir $(.92 ; 2232,957, \mathrm{p}<0,001)$.

Tablo 2. Etkinlikten vazgeçme ölçeği açımlayıcı faktör analizi sonuçları

\begin{tabular}{|c|c|c|c|c|c|}
\hline & $\frac{\frac{0}{0}}{\frac{\pi}{\pi}}$ & 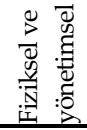 & 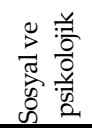 & 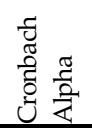 & 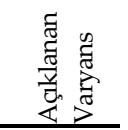 \\
\hline Etkinliği uzun süre bırakmak zorunda kaldığım bir & 6 & & & & \\
\hline sakatlık/hastalık geçirdim. & & .662 & & & $\% 41,26$ \\
\hline Etkinliği kalıcı olarak bırakmak zorunda kaldığım & 7 & & & & \\
\hline tedavisi mümkün olmayan bir sakatlık/hastalık geçirdim. & & .829 & & .92 & \\
\hline $\begin{array}{l}\text { Yaşlanma ya da olgunlaşmaya bağlı yaşadığım fiziksel } \\
\text { ve ruhsal değişimler sebebiyle etkinliği bırakmaya }\end{array}$ & 8 & & & & \\
\hline zorlandım. & & .758 & & & \\
\hline Coğrafi koşullarla ilgili avantajların kalıcı olarak değişmesi & 9 & & & & \\
\hline sebebiyle etkinliği bırakmaya zorlandım. & & .802 & & & \\
\hline Yönetmelikler/mevzuatların getirdiği sınırlamalar & 10 & & & & \\
\hline sebebiyle etkinliği bırakmaya zorlandım. & & .732 & & & \\
\hline $\begin{array}{l}\text { Başkaları tarafından öne sürülmüş ya da ispat edilmiş } \\
\text { tasvip edilmeyen davranışlar sebebiyle etkinliği }\end{array}$ & 11 & & & & \\
\hline bırakmaya zorlandım. & & .762 & & & \\
\hline Müsabaka/yarışmaya dayalı düzenlemeler/değişiklikler & 12 & & & & \\
\hline sebebiyle etkinliği bırakmaya zorlandım. & & .812 & & & \\
\hline Hukuki ya da ahlaki kuşkulara dayalı önlem alma & 13 & & & & \\
\hline sebebiyle etkinliği bırakmaya zorlandım. & & .794 & & & \\
\hline Etkinliğe olan ilgimi kaybetmedim ancak karşıma daha & 2 & & & & \\
\hline çekici aktiviteler çıktı. & & & .510 & .79 & $\% 23,70$ \\
\hline Daha çok kendi kontrolüm dışında gelişen sosyal baskılar & 3 & & & & \\
\hline sebebiyle etkinliği bırakmaya zorlandım. & & & .836 & & \\
\hline Daha çok kendi kontrolüm dışında gelişen sosyal psikolojik & 4 & & & & \\
\hline baskılar sebebiyle etkinliği bırakmaya zorlandım. & & & .805 & & \\
\hline Sosyal destek olmadığı için etkinliği bırakmaya zorlandım. & 5 & & .812 & & \\
\hline \multicolumn{4}{|c|}{ Toplam } & .91 & $\% 64,96$ \\
\hline
\end{tabular}


Yapılan açımlayıcı faktör analizi sonucu kesme değeri .30 olarak belirlenmiş, döndürülmüş bileşenler analizinde üç faktörlü yapı sergileyen ölçeğin, bir alt boyut altında en az 3 madde bulunması kuralına yönelik olarak madde 1 ölçekten çıkartılarak yapı sınanmıştır. Elde edilen bulguların ölçeğin iki alt boyut altında toplandığını gösterir nitelikte olduğu, güvenirlik katsayılarının ilk alt boyut için .92 , ikinci alt boyut için .79 düzeyinde olduğu ve açklanan varyans değerinin toplamda $\% 64,96$ olduğu belirlenmiştir.

\section{Doğrulayıcı faktör analizi}

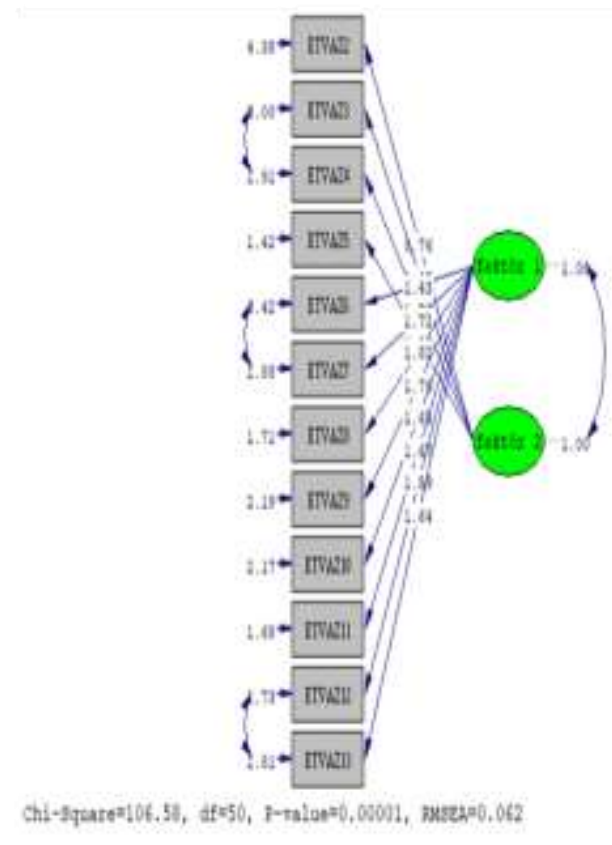

Doğrulayıcı faktör analizine dair bulgular

Yapılan açımlayıcı faktör analizi sonrası elde edilen yapının geçerliliğini ve doğruluğunu test etmek üzere doğrulayıcı faktör analizi yapılmıştır. Test tekrar test sonrası yapılan DFA'nın yapı geçerliliğine kanıt oluşturduğu görülmektedir (RMSEA .062, SRMR 0.033, NFI 0.98, CFI 0.99, NNFI 0.98, x²/df 2.13). 
Tablo 3. Uyum ölçüleri ve model uyumu için sınır değerleri

\begin{tabular}{lllll}
\hline Uyum Ölçüsü & $\begin{array}{l}\text { İdeal Uygunluk } \\
\text { Değerleri }\end{array}$ & $\begin{array}{l}\text { Kabul } \\
\text { Edilir Uyum }\end{array}$ & Uyumsuzluk & $\begin{array}{l}\text { Elde edilen } \\
\text { değerler }\end{array}$ \\
\hline RMSEA & $0-0.05$ & $0.05-0.09$ & $>0.10$ & 0.62 \\
\hline CFI & 1 & $0.90-0.99$ & $<0.90$ & 0.99 \\
\hline NNFI & 1 & $0.95-0.99$ & $<0.95$ & 0.98 \\
\hline $\mathrm{x}^{2} / \mathrm{df}$ & $<=2$ & $2-5$ & $5+$ & 2.13 \\
\hline Ozdar & &
\end{tabular}

Özdamar, 2016, s.185; Özdamar, 2013, s.242.

\section{Tartışma ve Sonuç}

Araştırma kapsamında etkinlikten vazgeçme ölçeğinin geliştirilmesine yönelik geçerlik ve güvenirlik çalışmaları yapılmıştır. Buna göre; test tekrar test yöntemiyle toplam 593 öğrenciden toplanan veriler, iki kısımda incelenmiş, ilk test verileri 293 katılımcidan elde edilmiş ve KMO-Barlett testine tabi tutulmuş ve örneklem büyüklüğünün analizi yapmak adına uygun olduğu $(.92 ; 2232,957, \mathrm{p}<0,001)$ belirlendikten sonra açımlayıcı faktör analizinden yararlanılmıştır. Açımlayıcı faktör analizi ile geçerli bir yapı oluşturulmaya çalışılmış, oluşturulan yapıya dair iç güvenirlik katsayıları sırasıyla 92 ve .79 bulunmasıyla yapıyı destekler düzeyde olarak belirlenmiştir. Yapılan açımlayıcı faktör analizinde kesme değeri 30 olarak alınmış, açıklanan varyans değerinin toplamda \%64,96 olduğu döndürülmüş bileşenler analizinde iki alt boyut altında toplandığı saptanmıştır. Test tekrar test yöntemiyle 300 katılımcı üzerinde yapılan ikinci veri toplama işleminden sonra yapı doğrulayıcı faktör analizi ile sınanmıştır. Doğrulayıcı faktör analizinin yapı geçerliliğine kanit oluşturduğu görülmektedir (RMSEA .062, SRMR 0.033, NFI 0.98, CFI 0.99, NNFI 0.98, x²/df 2.13).

Geliştirilmeye çalışılan etkinlikten vazgeçme ölçeğinin Stebbins'in (2008) kuramına dayandırılmış "iradeye bağlı etkinlikten vazgeçme", "sosyal ve psikolojik koşullara bağlı etkinlikten vazgeçme", "fiziksel koşullara bağlı etkinlikten vazgeçme", "coğrafi koşullara bağlı etkinlikten vazgeçme", "mevzuat/yasa/yönetmeliklere bağlı etkinlikten vazgeçme" olarak nitelendirilen alt boyut içerikleri baz alınarak hazırlanmıştır. Araştırma kapsamında gerçekleştirilen analizler sonucunda alt boyutlar fiziksel-yönetimsel ve sosyalpsikolojik olarak iki faktör altında incelenmiş ve isimlendirilmiştir.

Açık hava rekreasyonuna katılan ve bu etkinliklerden vazgeçen bireyler üzerinde yapılan araştırmada, terk etmenin geçici durumlarda bile kayıp ve 
suçluluk duygusuna yönelik deneyimler yaşadıklarını gözler önüne sermektedir. Vazgeçme olgusunun karmaşık bir yapıya sahip olduğunu kısa ömürlü, daha uzun ömürlü veya kalıcı olabildiğini ifade eden araştırma, çok boyutlu bir yapı olan vazgeçme durumunun en açı şekilde fiziksel bir çekimserlikle kendini gösterdiğini belirtmiştir. Diğer yandan, boş zaman katılımclarının bir partnerle boş zaman faaliyetlerine katıldıklarında vazgeçme öncülleri arasındaki etkileşimlerin karmaşıklığın daha belirgin hale geldiğini ifade etmişlerdir. Çalışma, araştırmamızla benzer olarak Stebbins'in vazgeçme tipolojisini desteklemekte ve geliştirmekte olan bir yapıya sahip olup, birden fazla unsurun vazgeçme deneyimi için etkili olabileceği fikrini ortaya koymaktadır (Lovelock, Jellum ve Carr, 2018).

Rekreasyonel amaçlı yapılan etkinliklerin pek çok önemli faydasına rağmen günümüzde bireylerin değişik sebepler nedeniyle bu tür etkinliklere katılmadıkları, engellendikleri yada vazgeçtikleri tespit edilmiştir (Koçak, 2005). Ancak alanyazında etkinlikten vazgeçme fenomenini ölçme bağlamında yetersiz kalındığı gözlemlenmektedir. Daha çok kısıtlayıcılar ve engeller üzerinde duran araştırmalar literatürde yerini almaktadır. Bu yönde yapılan çalışmaların az olmasına, etkinlikten vazgeçme olgusunun belirlenmesine yönelik ölçek geliştirme çalışmalarının sınırlı sayıda olması neden olarak gösterilebilir. Diğer yandan kısttlayıcılar ve engeller etkinlikten vazgeçme kavramını açılamaya yardımcı önemli unsurlar olarak karşımıza çıkmaktadır. Bu noktadan hareketle serbest zaman fiziksel aktivitelerine (SZFA) katılmayı kısıtlayan nedenleri araştırmaya yönelik geçerli ve güvenilir bir ölçek geliştirmeyi amaçlayan araştırmada 38 soruluk denemelik formu oluşturulmuş ve 190 geçerli ölçek toplanmış ve veriler açıklayıc faktör analizi ile çözümlenmiştir. Alt boyutlar araştırma bulgularından farklı olarak; fiziksel algı, tesis, gelir, aile, yetenek algısı, zaman, irade ve sosyal çevre olarak isimlendirilmiş, alt boyutların iç güvenirlik katsayılarının araştırmayla benzer şekilde .83 ila 93 aralığında değiştiği belirlenmiştir. Bununla birlikte alt boyutlar arası yapılan korelasyon analizinde faktörler arasında sıklıkla orta düzey bağıntı saptanmıştır. Toplam açılanan varyans etkinlikten vazgeçme ölçeğiyle benzer şekilde \%66,90 olarak elde edilmiştir (Öcal,2012).

Ülkemizde de uyarlama çalışmaları sıkça kullanılan Alexandris ve Carroll'ın (1997 geliştirdiği boş zaman kısıtlayıcıları ölçeği yedi faktörden oluşmakta ve varyansın \% 62.2'sini açıklamaktadır. Etkinlikten vazgeçme ölçeğinde yer alan sorularla benzeş sorulara sahip olan boş zaman kısıtlayıcıları 
ölçeğinin alt boyut isimleri sırasıyla; bireysel/psikolojik kısıtlamalar; katılım fırsatlarına ilişkin bilgi eksikliği, tesislerle/ hizmetlerle ilgili kısıtlamalar, finansal/erişilebilirlik kısıtlamaları, partner eksikliği, zaman sorunları ile ilgili kısıtlamalar, ilgi eksikliği/geçmiş deneyimler olarak adlandırılmıştır. Alt boyutlar için elde edilen Cronbach'ın alfa katsayıları etkinlikten vazgeçme ölçeğinin aksine 0.64 ile başlamış $0.85^{\prime} \mathrm{e}$ kadar ulaşmıştır.Tüm ölçeğin iç tutarlılık katsayısı 0.87 olarak bulunmuştur. Çalışma devamında rekreasyonel spor katılımına ilişkin kısıtlamaların algılanmasındaki demografik farklılıkları analiz etmiş ve kadınların erkeklere oranla, düşük eğitim düzeyine sahip olanların kısıtlama algısı önemli ölçüde artmıştır, kısıtların algılanması ile yaş arasında ters bir ilişki olduğu, evli bireylerin diğer bireylere nazaran daha yüksek k1sttlanma algısına sahip olduğu belirlenmiştir (Alexandris ve Carroll, 1997).

Yukarıda yer alan boş zaman kısıtlayıcıları ölçeğinin geçerlilik ve güvenilirlik testini uygulanması ve Türkçe'ye uyarlanmasının yapılması amaçlanmış, araştırmaya toplam 343 kişi katılmıştır. Ölçeğin Türkçe versiyonuna Türkçe'ye çevrildikten sonra açımlayıc faktör analizi güvenilirlik analizi ve doğrulayıc faktör analizi uygulanmıştır. AFA sonuçları incelendiğinde 0.5'den büyük tüm maddelerin çapraz korelasyon katsayıları incelendiğinde ve analizdeki tüm maddelerin kullanılmasına karar verilmiş, Temel Bileşen Analizi sonrasında özdeğeri 1'den büyük 7 faktör vardır ve bu faktörlerin toplam varyansa katkısı ekinlikten vazgeçme (EVÖ) ile benzer şekilde \%56.806 olarak belirlenmiştir. Ölçeğin toplamı için iç güvenirlik katsayısı yine benzer şekilde 0.876 olarak belirlenmiştir. CFA analizi sonucunda; CFI: 0.94, GFI: 0.96 ve NFI: 0.93 değerleri bulunmuştur ve Türkçe uyarlama çalışmasının geçerli ve güvenilir olduğu, 7 alt boyut ve orijinal ölçek gibi 29 maddeden oluştuğu sonucuna varılmıştır (Öztürk, Yıkılmaz ve Sarıkol, 2018).

Kentsel yaşam sürecinde bireylerin rekreasyonel etkinliklere katılımlarında engel oluşturabilecek faktörlerin belirlenmesinde kullanılabilecek boş zaman engelleri ölçeğinin geliştirildiği araştırmada, veriler elde edildikten sonra ölçeğin faktör yapısını test etmek için temel bileşenler analizinden faydalanılmış, analiz sonuçlarına göre, ölçek 8 faktörlü bir yapıdan oluşmakta ve ölçekte yer alan 28 madde toplam varyansın \%73'ünü açıkladığı belirlenmiştir. Faktör analizi sonucunda ortaya çıkan alt boyutlar 7 alt grupta incelenmiş, etkinlikten vazgeçme ölçeğinde elde edilen 2 alt boyuttan ayrıksı olarak (a) tesis, (b) ulaşım, (c) kentsel koşullar, (d) arkadaş eksikliği, (e) bilgi 
eksikliği, (f) para, (g) sosyal çevre ve (h) zaman olarak adlandırılmıştır. Cronbach Alpha iç tutarlılık katsayısı yine benzer şekilde .76 ile .88 arasında değiştiği belirlenmiştir. Sonuç olarak, "Boş Zaman Engelleri Ölçeği-28" (BEÖ28) olarak adlandırılan ölçeğin, kentsel yaşam sürecinde öğretim elemanlarının boş zaman etkinliklerine katılımlarında engel oluşturabilecek faktörleri belirlemek için geçerli ve güvenilir bir ölçek olduğu belirlenmiştir (Gürbüz ve Karaküçük, 2007). Boş zaman engelleri ölçeğinin yapı geçerliğinin test edilmesine yönelik yapılan bir diğer araştırmada; "Boş Zaman Engelleri Ölçeği"nin doğrulayıcı faktör analizi ile yapı geçerliğini test etmek (Gürbüz, Öncü ve Emir, 2012) amaçlanmış ve yapının geçerli ve güvenilir olduğu belirlenmiştir. Dolayısıyla etkinlikten vazgeçme, engeller ve kısıtlayıcılar iç içe geçmiş unsurları ölçmede etkili ve verimli bir kaynak sunmaktadır.

Serbest zaman kısıtlayıcıları ve boş zaman engelleri ölçüm araçlarından yola çıkılarak dizayn edilen "Köyde Rekreasyon Engelleri Ölçeğinin- KREÖ” ölçeğinin geçerlilik ve güvenirlilik çalışmasını yapan araştırma kapsamında Antalya' da bulunan Karatepe ve Gökçam Köyünden toplam 231 katılımcı çalışma grubunu oluşturmaktadır. Çalışmada KMO (0.798) ve Bartlett küresellik testlerinin ( $\left.X^{2}=9503.612, S D=990, p=0.000\right)$ sonuçlarına göre ölçeğe açıklayıcı faktör analizi (AFA) uygulanabilir olduğu için AFA uygulanmış, modelin geçerlilik ve güvenirliliği yapılmış ve KREÖ'nin alt boyutları ortaya konulmuştur. Ölçeğin iç tutarlılığ1 (0.847) ve açıklanan varyans oranı \%78.56 olarak bulunmuş ve sonuçlar 0.01 ve 0.05 anlamlılık düzeyinde sorgulanmıştır. Sonuç olarak ölçek toplam etkinlikten vazgeçme ölçeğinde yer alan alt boyutlardan oldukça fazla bir alt boyut sayısı ortaya koyan KREÖ 11 faktörden oluşmaktadır ve sonuçlar KREÖ'nün Türk popülasyonu için geçerli ve güvenilir olduğunu göstermektedir (Öz ve Ardahan, 2019). Yaşanılan yerin etkinlikten vazgeçme hususunda önemli bir parameter sunduğu ifade edilebilir. Dolayısıyla etkinlikten vazgeçme fenomeni ölçülürken yaşanılan yerin, bölgenin de sinanması önemli olacaktır.

Bir rekreasyonel etkinlik olarak bireyin seyahate çıkma kararı birçok faktörün etkisi altında olan çok yönlü bir süreç olduğu bilinmektedir. Seyahat kısıtlayıcıları; bireyin tam bir seyahat deneyimi yaşamasını engelleyen, seyahate çıkma sıklığını azaltan ve/veya seyahate çıkma kararı almasına engel olan faktörler olarak tanımlanmaktadır ve bu çalışmada, Türk vatandaşlarının yurt dışı seyahatlere çıkmalarını kısıtlayan faktörler, bağımsız seyahat 
eden yerli gezgin örnekleminde incelenmeye çalışılmıştır. Etkinlikten vazgeçme ölçeğinde yer alan "Yönetmelikler/mevzuatların getirdiği sınırlamalar sebebiyle etkinliği bırakmaya zorlandım." Maddesiyle benzer olarak bağımsız seyahat eden yerli gezginlerin yurt dışı seyahat kısıtlayıcılarının; harçlar ve vize uygulamaları dolayısıyla seyahat kısıtlılığı yaşadığı belirlenmiştir. Yönetimsel bir unsur olan bu durum etkinlikten vazgeçme ölçeğinde de benzer bulgular ortaya koymuştur. Dolayısıyla bu noktada yönetimsel kolaylaştırıcılara ihtiyaç duyulduğu ortadadır. Aynı zamanda sosyal faktörler, risk algısı ve ulaşım, zaman ve bütçe diğer kısıtlayıcılar arasındadır. Ölçeğin analiz bulgularına göre 18 maddelik ölçeğin Cronbach Alpha katsayısı ,801 olarak hesaplanmıştır. Ölçek, 4 faktör altında toplanmış ve etkinlikten vazgeçme ölçeği ile benzer şekilde toplam varyansın \%72,73'ünü açıklamıştır. Maddelerin eş kökenlilikleri incelendiğinde, 15 maddenin eşkökenliğinin 0,518 ile 0,923 arasında değiştiği anlaşılmaktadır. KMO örneklem yeterliliği yine benzer bulgular ortaya koymuş ve $\% 81,5$ olarak hesaplanmıştır. Bartlett küresellik test değeri 1364,572 olup; bu değer 0,0001 düzeyinde anlamlıdır. Bu noktada iç güvenirlik katsayısı ölçeğin tamamı için .787 olarak belirlenmiştir (Harman, 2014). Rekreasyonel etkinlik olarak sayabileceğimiz pek çok etkinlik türünde yapısal kısıtlamaların yer aldığı görülmektedir. Bu noktadan hareketle daha fazla planlamaya ve yönetimsel, toplumsal değişime ihtiyaç duyulduğu söylenebilir.

Etkinlikten vazgeçme kavramına benzer olarak mücadeleyi bırakma alt boyutuna sahip olan amaçlar için mücadele ölçeğinin geliştirilmesine yönelik çalışmalar, üniversite öğrencilerinin katılımıyla gerçekleştirilmiş, örneklem büyüklügünün $(.90 ; 2396,453$, p<0,001).90 düzeyinde KMO oranı verdiği belirlenmiş, verilerin analizinde açımlayıc faktör analizi sonunda $\% 61.05$ oranında açıklanan varyansa ulaşıldığı, doğrulayıcı faktör analizi bulgularına göre ise RMSEA değerinin 0.051; serbestlik derecesinin 116 ve kay kare değerinin ise 2.07 olduğu bulunmuştur. amaçlar için mücadele etme ölçeği doğrulayıc faktör analizine bağlı olarak gerçekleşen uyum iyiliği değerleri; NFI, 0.97; NNFI, 0.98; CFI, 0.98; IFI, 0.98; GFI, 0.94 ve AGFI değeri ise 0.92 olarak bulunmuştur. İç tutarlık katsayıları ise .86 ile .88 arasında değiştiği gözlemlenmiş etkinlikten vazgeçme kavramıla benzeş şekilde "Mücadeleyi B1rakma" olarak isimlendirilen bir alt boyutun yer aldığı, üç alt boyuta sahip 
“Amaçlar İçin Mücadele Etme Ölçeği'ne” ulaşılmıştır. Etkinlik vazgeçme ölçeğine paralel olarak benzer bulgular ortaya koyan analiz sonuçlarına göre ölçeğin geçerli ve güvenilir olduğu ifade edilebilir (Eryılmaz, 2015).

Sportif faaliyetlerden vazgeçme, sportif rekreasyonel uygulamaların d1şında kalmayı tercih etme durumlarının araştırıldığı pek çok çalışmaya rastlanmaktadır. Onlardan biri olan üniversite öğrencilerinin sportif aktivitelerde bulunma tercihlerinin incelendiği bu çalışmaya 538 öğrenci katılmış, araştırmacı tarafından geliştirilen "Spor Yapma ve Yapmama Nedenleri Ölçeği" kullanılmış ve ölçeğin geçerlik ve güvenirlik çalışması yapılmıştır. Etkinlikten vazgeçme ölçeğine paralel olarak "Spor Yapmama Nedenleri Ölçeği" toplam 12 maddeden oluşmakta olup 4 alt boyutu bulunmaktadır. Bu alt boyutlar "Fiziki nedenler, "Zaman yetersizliği", "Kişisel özellikler" ve "Maddi ve sosyal çevre nedenleri" olarak isimlendirilmiş ve ölçeğin alt boyutlarında ve toplam puanından alınacak yüksek puanlar spor yapmama nedenini açıklamaktadır. Fiziki nedenler etkinlikten vazgeçmenin de önemli bir çıktısı olarak değerlendirilmektedir. Diğer taraftan KMO-Barlett katsayısının etkinlikten vazgeçme ölçeğinin aksine 0,70; 568,978 olduğu görülmektedir. Bu değer örneklem grubunun yeterli büyüklükte olduğuna sınır düzeyde olsa da kanıt oluşturmaktadır. spor yapmama nedenleri ölçeğinin faktör analizi sonrası toplam varyansın 56'sını açıklayan özdeğeri 1.00'in üzerinde olan 4 faktörlü bir yapı ortaya çıkmıştır (Gülbahçe, 2011). Spor gibi pek çok etkinliğin bırakılmasındaki nedenler ve sonuçlar detaylı olarak araştırılması gereken önemli faktörlerdir. Dolayisıyla etkinlikten vazgeçme ölçeği literature bu bağlamda katkı sunacağı düşünülen bir ölçüm aracıdır. Etkinlikten vazgeçmenin yaratacağı olumsuz durumlara karşı koyabilmek, hem kişisel hem toplumsal açıdan son derece büyük bir öneme sahiptir.

Bir diğer araştırmada, profesyonel futbolu bırakan bireylerin bırakma yaşantılarını algılamalarını ölçebilecek geçerli ve güvenilir bir ölçme aracı geliştirmek amaçlanmış ve profesyonel futbolu bırakmış 147 birey gönüllü olarak katılmıştır. Ölçeğin geçerliğini test etmek amacıyla ölçekte bulunan 40 maddeye ilişkin yapılan faktör analizinde; ölçeğin 5 faktörlü olduğu tespit edilmiş ve madde sayısı da 23'e indirilmiştir. Ölçeğin iç güvenirlik katsayısı düşük bir değerde olup, etkinlikten vazgeçme ölçeğinin aksine 0,6576 olarak tespit edilmiştir. Bırakmada zamanlama, futbolculuğa özlem, bırakmaya olumsuz tepkiler, bırakmaya uyum, bırakma sonrası sağlık alt boyutlarından oluşan,toplam varyansın \%60,41 açıllandığı, KMO-Barlett testi 0,83; 1375,224 
olarak tespit edilmiştir (Tunçkol ve Güven, 2014). Geçerli ve güvenilir bir ölçüm aracı ortaya koyan araştırma bulguları; futbol gibi etkinlikleri bırakmış bireylerin, sarsıcı deneyimler yaşaması, duygusal yönden ve sağlık açısından problem yaşadığı bir sürece girmesi muhtemel olarak gözükmektedir. Bu anlamda alanın genişletilerek araştırmalar yapılması gerekliliği göze çarpmaktadir.

Benzer bir araştırmada ise fitness salonlarına üye bireylerin fitnessı bırakma nedenleri incelenmiş, üyelik maliyetlerinin ve stüdyo koşullarının çok da geçerli bir vazgeçme nedeni olmadığı, diğer taraftan yoğun olarak zaman planlamasında yaşanan sıkıntılar bırakma sebepleri arasında gelirken, sağlık sorunları, ve eğitimin diğer yaşam alanlarına göre önceliklendirilmesi fitnesstan vazgeçme sebepleri arasında yer almaktadır. Veriler, çeşitli bırakma nedenlerinin katılımcılar tarafından farklı bir şekilde değerlendirildiğini ve bırakma kararının nedenleri hakkında çok az genel bilgi olduğunu göstermektedir (Zarotis ve diğ., 2017). Dolayısıyla araştırmalar boş zamanlara ayrılan sürelerin yetersizliğini, etkinlikten vazgeçme eşiğinin özellikle Türk toplumda çok düşük olduğunu ortaya koyar niteliktedir. Bu bağlamda nedenler belirlenerek, olumsuz sonuçlar ortaya koyabilecek durumların ortadan kaldırılması yönünde çalışmaların yapılması gerekliliği doğmuştur. Bu nedenleri belirlemede etkili bir araç olacağı düşünülen etkinlikten vazgeçme ölçeği alanyazına katkı sağlamak ve etkinlikten vazgeçme nedenlerini belirlemek kullanılmak üzere tasarlanmıştır.

Sonuç olarak katılımcıların etkinlikten vazgeçmelerinin belirlenmesine yönelik geliştirilen ölçüm aracının, etkinlikten vazgeçme fenomenini ölçmede geçerli ve güvenilir bir araç olduğu belirlenmiştir. Araştırmacıların farklı örneklem grupları üzerinde etkinlikten vazgeçme fenomenini ölçerek alana katkı sağlaması, program planlama alanında söz konusu akademik çalışmalardan yararlanarak, etkinliklerin kalitesini ve yelpazesini arttırmada, etkinlikten vazgeçme unsurlarını en aza indirmede etkin uygulamalar ortaya koymaları önerilmektedir. 


\title{
EXTENDED ABSTRACT
}

\section{Leisure Abondonment Scale Validity And Reliability Analysis}

\author{
Ali Selman Özdemir - Tebessüm Ayyıldız Durhan - Suat Karaküçük \\ International Kıbris University, Gazi University
}

While leisure researchers have put much effort over the last two decades into understanding the motivations for and constraints to leisure participation, less research has been undertaken exploring the phenomenon of discontinuation of leisure activities, or what we will refer to as "abandonment." Leisure abandonment is a point in a person's life course, at which he leaves a particular leisure activity. Observations to date suggest this is accomplished by way of one of the following alternatives: 1) deciding consciously to quit the activity, 2) being forced from it by external circumstances, 3) or leaving the activity by drifting away from it (Stebbins, 2008). Participation and abandonment are not unrelated, however, with constraints acting as critical determinants in the decision to cease or reduce frequency of participation (Fedler \& Ditton, 2001; Raymore et al., 1993).

The decision to cease participating in an activity has been described as being conceptually different from the decision not to begin participating in an activity (Backman \& Crompton, 1989). The nature of abandonment is less well understood than its conceptual counterparts; in particular, the process of abandonment, how it is managed, who is involved, and how it manifests on the lives of individuals and their other leisure choices are aspects that have not been thoroughly explored (Brent et al., 2018).

The focus of leisure abandonment is on what "is wrong" with a current activity" - to learn why people leave it - rather than on the allure of another activity, whether as replacement, substitute, or addition. What is more, it appears that most people face such abandonment, such personal crisis, at least once during their life course (Stebbins, 2008).

The introduction of this scale in the literature is important for the process of clarifying recreational constraints, determining negotiating strategies related to them, reducing the effects of constraints on activity participation or 
determining ways to prevent these effects. Similarly, the motivations of individuals to participate in leisure and to main- tain their involvement have been empirically and conceptually explored (Chen ve Pang, 2012).

When the literature is analyzed, it is seen that there is a limited number of studies on the behavior of individuals to end their participation in recreational activities or to abandon their activities (Boothby ve diğ., 1981; Tsai ve Coleman, 1999; Fedler ve Ditton, 2001; Stebbins, 2008; Sutton ve diğ., 2009; Beaton, 2010). Although Stebbins (2008) is the first researcher to suggest a typology for abandonmen, and he states that there is a need to investigate the "personal crisis of abandoning an activity that is persisted." In this study, it is aimed to test the validity and reliability of the 'Abandonment Scale' developed by taking advantage of the possibilities that Stebbins (2008) put forward on the phenomenon of abandonment. With this scale, it is aimed to identify the key factors in this process and to improve the empirical findings of Stebbins' (2008) typology, especially by researching how individuals are experienced and managed to abandon a leisure activity.

The data in the study were obtained from 593 students in Zonguldak Bülent Ecevit University, who studied at different faculties. The experimental form created was tested on 293 participants with the test-retest method and analyzes were performed. In order to prove the validity of the structure, a second test was performed on the same group and confirmatory factor analysis was applied in line with the data obtained from 300 participants.

Within the scope of the research, validity and reliability studies were carried out to improve the abandonment scale. According to this; With the testretest method, the data collected from a total of 593 students were examined in two parts, the first test data was obtained from 293 participants and subjected to KMO-Barlett test and it was determined that the sample size was suitable for analysis $(.92 ; 2232,957, \mathrm{p}<0.001)$. exploratory factor analysis was used. A valid structure was tried to be created with exploratory factor analysis, and the internal reliability coefficients of the constructed structure were determined as supporting level by finding .92 and .79, respectively. In the exploratory factor analysis, the cut-off value was taken as .30, and it was found that the explained variance value was $64.96 \%$ in total, and it was found to be gathered under two sub-dimensions in the rotated components analysis. After the second data collection on 300 participants with the test-retest method, the structure was tested by confirmatory factor analysis. Confirmatory factor 
analysis appears to provide evidence of construct validity (RMSEA .062, SRMR 0.033, NFI 0.98, CFI 0.99, NNFI 0.98, x2 / df 2.13).

The scale of leisure abandonment that is tried to be developed is based on the sub-dimensions of Stebbins (2008) theory as; "Volitional Leisure Abandonment", "Social Psychological Leisure Abandonment", "Physical Leisure Abandonment", "Geographic Leisure Abandonment", "Regulatory Leisure Abandonment". As a result of the analyzes carried out within the scope of the research, the sub-dimensions were analyzed and named under two factors as physical-administrative and social-psychological.

As a result, it was determined that the measurement tool developed to determine the participants' abandonment from the activity is a valid and reliable tool for measuring the abandonment phenomenon. It is recommended that researchers contribute to the field by measuring the phenomenon of abandonment on different sample groups, and by taking advantage of the mentioned academic studies in the program planning, they demonstrate effective practices in increasing the quality and range of the activities and minimizing the abandonment factors.

\section{Kaynakça / References}

Alexandris, K. ve Carroll, B. (1997). Demographic differences in the perception of constraints on recreational sport participation: Results from a study in Greece. Leisure Studies, 16(2), 107-125.

Backman, S., Crompton, J. (1989). Discriminating between continuers and discontinuers of two public leisure services. Journal of Park and Recreation Administration, 7(4), 56-71.

Beaton, A. A. (2010). Building a theory of participation in physically active leisure. Doctoral dissertation, Department of Tourism, Leisure, Hotel and Sport Management, Business School, Griffith University, Australia.

Boothby, J., Tangutt, M. F., ve Townsend, A. R. (1981). Ceasing participation in sports activity: Reported reasons and their implications. Journal of Leisure Research, 13, 1-14.

Lovelock, B., Jellum, C. ve Carr A. (2018) Pulling the pin on active outdoor leisure: Building an understanding of leisure abandonment from the narratives of outdoor recreationists. Leisure Sciences, 40(5), 406-422.

Chen, M., ve Pang, X. (2012). Leisure motivation: an integrative review. Social Behavior and Personality: An International Journal, 40(7), 1075-1081. 
Eryılmaz, A. (2015). Amaçlar için mücadele ölçeğinin geliştirilmesi. Uşak Üniversitesi Sosyal Bilimler Dergisi, 8(4), 233-244.

Fedler, A. J. ve Ditton, R.B. (2001). Dropping out and dropping in: A study of factors for changing recreational fishing participation. North American Journal of Fisheries Management, 21(2), 283-292.

Gülbahçe, Ö. (2011). Üniversite öğrencilerinin sportif aktivitelerde bulunma tercihlerinin bazı psiko-sosyal değişkenler açısından incelenmesi. Atatürk Üniversitesi Eğitim Bilimleri Enstitüsü, Doktora Tezi, Erzurum.

Gürbüz, B., Karaküçük, S. (2007). Boş zaman engelleri ölçeği-28: Ölçek geliştirme, geçerlik ve güvenirlik çalışması. Gazi Beden Eğitimi ve Spor Bilimleri Dergisi (Gazi BESBD), 12(1),3-10.

Gürbüz,B., Öncü, E. ve Emir, E. (2012). Leisure constraints questionnaire: Testing the construct validity/boş zaman engelleri ölçeği: Yapı geçerliğinin test edilmesi. 12th International Sport Sciences Congress December 12-14, 2012 Denizli/Turkey.

Harman, S. (2014). Yurt dışı seyahat kısıtlayıcıları: Bağımsız seyahat eden yerli gezginler üzerinde yapılan bir araştırma.Uluslararası Alanya Işsletme Fakültesi Dergisi, 6(1),63-78.

Koçak, S. (2005). Perceived barriers to exercise among university members. ICHPER-SDJ, 41(1), 34-36

Lovelock,B., Jellum, C. ve Carr, A. (2018). Pulling the pin on active outdoor leisure: building an understanding of leisure abandonment from the narratives of outdoor recreationists. Leisure Sciences, 40(5), 406-422, DOI: $10.1080 / 01490400.2016 .1229640$.

Öcal, K. (2012). Ölçek geliştirme: Serbest zaman fiziksel aktivite kısıtlayıcıları (SZFA-K). Spor Bilimleri Dergisi Hacettepe Journal of Sport Sciences, 23(2), 50-60.

Öz, N.D. ve Ardahan, F. (2019). Köyde rekreasyon engelleri ölçeği geçerlilik ve güvenirlilik çalışması. Mediterranean Journal of Humanities, 9(1), 141-151.

Öztürk, M.A., Yıkılmaz, A. ve Sarıkol, E. (2018). Turkish validity and reliability study of the leisure constraint questionnaire. Journal of Education and Learning, 8(1),150-157.

Raymore, L., Godbey, G., Crawford, D., ve Von Eye, A. (1993). Nature and processes of leisure con- straints: An empirical test. Leisure Sciences, 15, 99-113.

Stebbins, R. A. (2008, November). Leisure abandonment: Quitting free-time activity that we love. LSA Newsletter No. 81. Leisure Reflections, 19, 14-19. 
Sutton, S. G. (2007). Constraints on recreational fishing participation in Queensland, Australia. Fisheries, 32(2), 73-83.

Tsai, E. H. ve Coleman, D. J. (1999). Leisure constraints of Chinese immigrants: An exploratory study. Loisir et societe/Society and Leisure, 22(1), 243-264.

Tunçkol, H.M., Güven, Ö. (2014). Profesyonel futbolu bırakma yaşantısını algılama ölçeği geçerlik ve güvenirlik çalışması.Spor ve Performans Araştırmaları Dergisi, 5(1), 49-55.

Zarotis, G., , Athanailidis, I., Tosunidis, A. ve Mastrogiannopoulos, N. (2017). Drop-out in fitness-sport. Comparing the general relevance of reasons for quitting. TRENDS in Sport Sciences, 4(24), 175-181,ISSN 22999590.DOI: 10.23829/TSS.2017.24.4-5.

\section{Kaynakça Bilgisi / Citation Information}

Özdemir, A. S., Ayyıldız Durhan, T. ve Karaküçük, S. (2020). Etkinlikten vazgeçme ölçeği geçerlik güvenirlik çalışması. OPUS-Uluslararası Toplum Araştırmaları Dergisi, 15(23), 1940-1958. DOI: 10.26466/opus.689357 